\title{
Performance Analysis of Steam Power Plants Using Ideal Reheat-Rankin Cycle
}

\author{
Dr. Fawaz Sultan
}

\author{
Technical College of Engineering, Mosul
}

\begin{abstract}
In this paper, a hypothetical examination has been done to assess the execution of the power plants that are chipping away at Reheat-Rankin cycle. The execution of cycle was dissected for various (warm, evaporator, condenser weights) values and also warm temperature qualities to demonstrate its impact on cycle warm proficiency. In this work, the heater weights qualities was accepted limited between (10to $26 \mathrm{MPa}$ ), the pressure proportion (warm stage weight to evaporator weight) was expected fluctuated in wide range from (0.1 to 1.0), while the condenser weight was accepted shifted between (5 to 25 $\mathrm{kPa}$ ). And, a variety in warm temperature esteem was done between scopes of (400-600oC) at low weight turbine. The outcomes demonstrate that the warm productivity is considerably upgraded when the pressure proportion lies between (0.25-0.35) and the ideal proficiency is gotten when the pressure proportion and evaporator weight are equivalent to $(0.33$ and $26 \mathrm{MPa}$ ) separately .
\end{abstract}

Keywords-Reheat temperature, Condenser weight, Boiler weight, Reheat-Rankin cycle proficiency.

\section{INTRODUCTION}

Fundamental steam control plants work in view of Rankin cycle. Numerous methods are being utilized to expand the effectiveness of the steam cycle plant at various conditions. Most extraordinary of these procedures are warming as well as decreasing the irreversibility .The warming procedure builds the proficiency of cycle by raising the mean temperature of the warmth expansion prepare by expanding the steam temperature at the principal organize turbine outlet furthermore, expanding the productivity of the extension procedure in the steam turbine [1]. The impacts of evaporator temperature, weight, and the irreversibility's on the execution of single and twofold warm irreversible Rankin cycles are researched. The impacts of first and second stage warm weights on the general execution and proficiency increment rates for the single and twofold warmed Rankin cycles are additionally examined [2]. A thermodynamic examination of a solitary warm Rankin cycle for the steam control plants in light of the first and second laws of thermodynamic has been performed. The vitality and energy efficiencies for various framework parameters have been concentrated, for example, heater temperature, kettle weight, mass part proportion and work yield, [3]. The vitality and energy investigation of a perfect Rankin cycle with warm had been exhibited notwithstanding break down the framework segments independently and to distinguish and measure the locales having biggest vitality and energy misfortunes at cycle. The impact of changing the condenser weight on this examination will likewise be introduced [4]. Another specialists were clarified the endeavors of progression in the best in class in steam turbine innovation, which is identified with the change in the thermodynamic proficiency by expanding the temperature and weight at which warmth is added to the power cycle. The steam turbine was explored for ultrasupercritical power plants and reported warmth rate change of single and twofold warm steam cycles with ultrasupercritical steam conditions on their work [5]. Energy investigation and parametric examination have been conveyed for supercritical Rankin cycle with warm, open and shut sustain water radiators of higher power era for present day steam control plants at supercritical, ultra supercritical and progressed ultra-supercritical temperatures and weights [6]. The vitality and energy examination of a warm regenerative vapor control cycle has been portrayed. The plant comprises of one evaporator sustain pump, one supercritical kettle, two steam turbines with a warmed in the middle of, two nourish water radiators and a condenser. The vitality and energy adjust think about has been completed for every segment of the plant. Vitality effectiveness, energy proficiency and the irreversibility comes about got from the reproduction has been displayed as diagrams [7]. The streamlining of warm regenerative warm power plants has been broke down for the subcritical weight territory, [8-9]. The exegetic examination and streamlining has been accomplished for the supercritical Rankin cycle, [10]. In this examination, the execution of the steam control plant chipping away at Reheat-Rankin cycle has been broke down for various (heater weight, condenser weight, and warm 
temperature) to demonstrate this impact on cycle warm effectiveness.

\section{RANKIN CYCLE ANALYSIS}

The Rankin cycle is a warmth motor with a vapor control cycle. The normal working liquid is water. The cycle comprises of four procedures as appeared in Figs. (1a) and (1b).

1 to 2: Isentropic pressure (Pump), amid the isentropic pressure handle outer work is done on the working liquid (in fluid stage) by a method for working pump.

2 to 3: Isobaric warm supply (Steam Generator or Boiler), amid this procedure the warmth from the high temperature source is added to the working liquid at a consistent weight to change over it into superheated steam.

3 to 4: Isentropic extension (Steam turbine), an isentropic procedure in which the entropy of working liquid in a perfect world stays consistent.
4 to 1: Isobaric warm dismissal (Condenser), an isobaric procedure, in which the working liquid change over from steam to fluid stage at consistent weight.

In the examination of a warmth motor cycle, it is expected that the liquid stream takes after the progression condition relevant to relentless state conditions. All the power plants are expected to keep running under consistent state conditions. The beginning and closing down working condition is exempted where deviations from an enduring state can't be maintained a strategic distance from. With reference to the Rankin cycle that appeared in Figs. (1a) and (1b), the control of the stream can be practiced by a valve. Fractional nearer of the valve would diminish the stream of steam in the turbine and power yield. In the perfect Rankin cycle, working liquid takes after reversible an adiabatic or isentropic way in the turbine and is subjected to lower weight and temperature in the condenser.

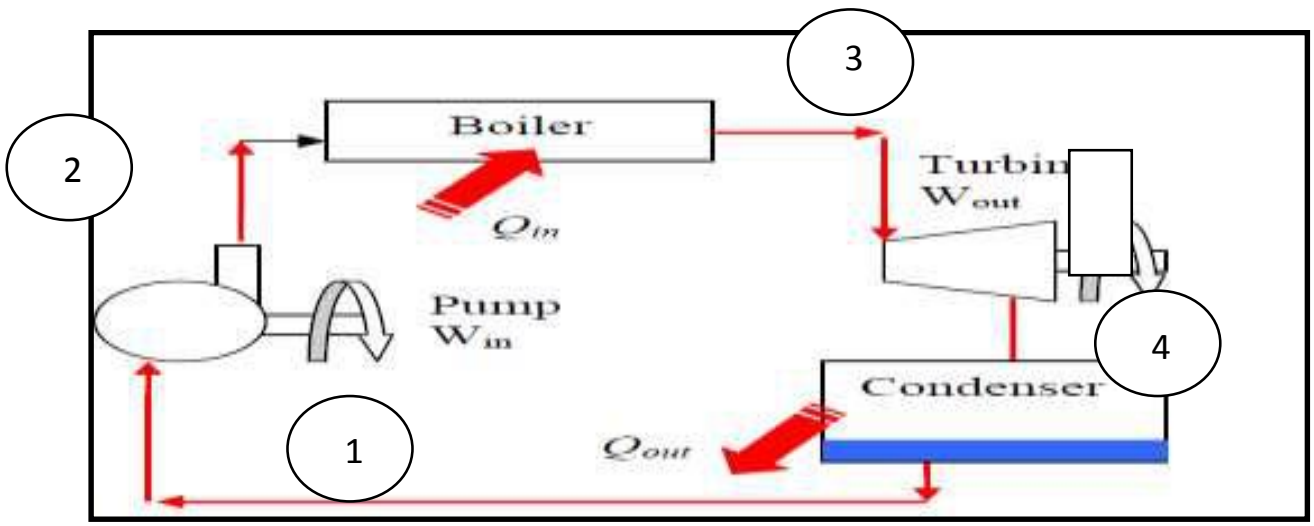

Fig. (1a) Rankine cycle schematic chart

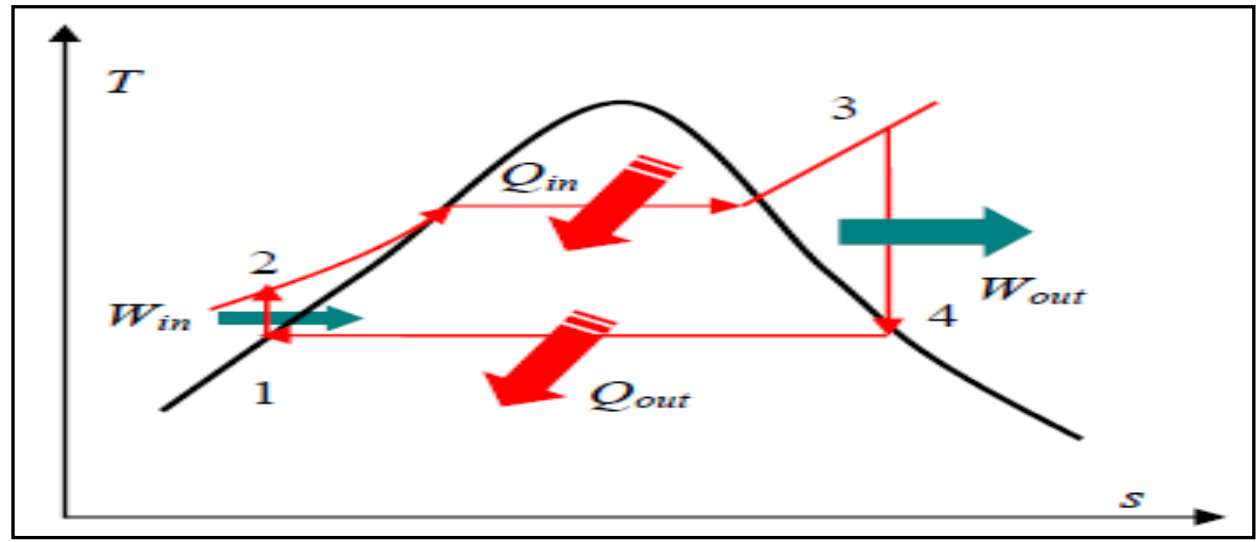

Fig. (1b) Rankin cycle T-S chart.

$$
\mathrm{h}_{\mathrm{e}}-\mathrm{h}_{\mathrm{i}}=\left(\mathrm{W}_{\mathrm{in}}-\mathrm{W}_{\text {out }}\right)+\left(\mathrm{Q}_{\mathrm{in}}-\mathrm{Q}_{\text {out }}\right)(\mathrm{kJ} / \mathrm{kg})(1)
$$

At that point the protection of energy relation for turbine and pump can be The motor and potential vitality contrasts between the bay and outlet are unimportantly little and also expect the turbine and pump procedures is to be isentropic in a perfect world. In this manner by applying the principal law of thermodynamics for turbine [11]: 


$$
\begin{gathered}
\text { Communicated as: } \mathrm{W}_{\text {turbine }}=\mathrm{h}_{3}- \\
\mathrm{h}_{4}\left(\frac{\mathrm{kJ}}{\mathrm{kg}}\right) \ldots \ldots \ldots \ldots \ldots \ldots \ldots \text { (2) }
\end{gathered}
$$

The condenser is an expansive shell-and-tube sort warm exchanger. This is situated beside the turbine so as to get a vast stream rate of low weight steam. This steam in the condenser goes under a stage change from vapor to fluid water. Outside cooling water is pumped through a huge number of tubes in the condenser to transport the warmth of buildup of the steam far from the plant. After leaving the condenser, the condensate is at a low temperature and weight. Evacuation of this condensate might be considered as keeping up the low weight in the condenser constantly. The stage change thusly relies on upon the exchange of warmth to the outside cooling water. The dismissal of warmth to the surroundings by the cooling water is basic to keep up the low weight in the condenser. Applying the

$$
\mathrm{Q}_{\text {boiler }}=\mathrm{h}_{3}-\mathrm{h}_{2}\left(\frac{\mathrm{kJ}}{\mathrm{kg}}\right)
$$

\section{RANKIN WITH REHEAT CYCLE ANALYSIS:}

In basic Rankin cycle, after the isentropic development in turbine, steam is specifically nourished into condenser for buildup prepare, however in warm framework, two turbines (high weight turbine and low weight turbine) are utilized for enhancing productivity. Steam, after development from high weight turbine, is sent again to heater and warmed till it comes to superheated condition. It is then left to grow in low weight turbine to achieve condenser weight. The cycle comprises of six procedures as appeared in Figs. (2a) and (2b).

1 to 2: Isentropic pressure (in a pump) An isentropic procedure, in which the entropy of working liquid stays consistent.

2 to 3: Constant weight warm expansion (in a kettle) An isobaric procedure, in which the weight of working liquid stays consistent.

3 to 4: Isentropic development (in a high weight turbine).

4 to 5: Reheat steam (in a heater).

5 to 6: Isentropic development (in a low weight turbine).

6 to 1: Constant weight warm dismissal (in a condenser).

The Rankin cycle has been altered to deliver more yield work by presenting two steam turbine stages utilizing middle of the road warming. Essentially, in this work the changed Rankin cycle, the full development of steam is hindered in the high-weight turbine and steam is released after incomplete extension. This fumes steam is gone through an icy warm line to the steam generator where it picks up warmth while going through hot tubes. This

$$
\mathrm{W}_{\text {pump }}=\mathrm{h}_{2}-\mathrm{h}_{1}\left(\frac{\mathrm{kJ}}{\mathrm{kg}}\right) \ldots \ldots \ldots \ldots \ldots \ldots \ldots
$$

consistent stream first law of thermodynamics to the consolidating steam empowers [11]:

$$
\mathrm{Q}_{\text {cond. }}=\mathrm{h}_{4}-\mathrm{h}_{1}\left(\frac{\mathrm{kJ}}{\mathrm{kg}}\right)
$$

The estimation of (Qcond.) is negative on the grounds that $\mathrm{h} 4>\mathrm{h} 1$. In this manner, predictable with sign tradition, (Qcond.) speaks to a surge of warmth from the consolidating steam. This warmth is consumed by the cooling water going through the condenser tubes.

Applying the consistent stream first law of thermodynamics condition (1) to the steam generator with shaft work equivalent to zero, then the steam generator warm exchange is given by the accompanying condition [12]

warmed steam is provided to a low weight turbine for full development and achieves the condenser weight. The changed Rankin T-S graph demonstrates some expansion in the zone which is accomplished on account of the presentation of the warming of steam. These outcomes in low weight turbine development work. Consequently, warm builds work out.

This results in low pressure turbine expansion work. Thus, reheat increases work output because of low pressure turbine expansion work. The use of reheat also tends to increase the average temperature at which heat is added. If the steam from the low-pressure turbine is superheated, the use of reheat may also increase the average temperature at which heat is rejected. It may reduce or increase the thermal efficiency depending on the specific cycle conditions, thermal (heat addition and heat reduction temperature) or mechanical (condenser vibrations and air leakage, pump vibrations, turbine blade vane deflection etc.). Indeed the work net of the reheat cycle is the algebraic sum of the work of the two turbines and the pump work and the total heat addition is the sum of the heat added in the feed-water and reheat passes through the steam generator. Thus, the thermal efficiency of the reheat cycle can be presented as follows [12]:

$$
=\frac{W_{\text {high pressuer turbine }}+W_{\text {low pressuer turbine }}-W_{\text {pump }}}{Q_{\text {boiler }}+Q_{\text {reheat }}} \ldots \ldots
$$

Or,

$$
\eta_{\text {th }}=\frac{\left(h_{3}-h_{4}\right)+\left(h_{5}-h_{6}\right)-\left(h_{2}-h_{1}\right)}{\left(h_{3}-h_{2}\right)+\left(h_{5}-h_{4}\right)} \ldots(7)
$$




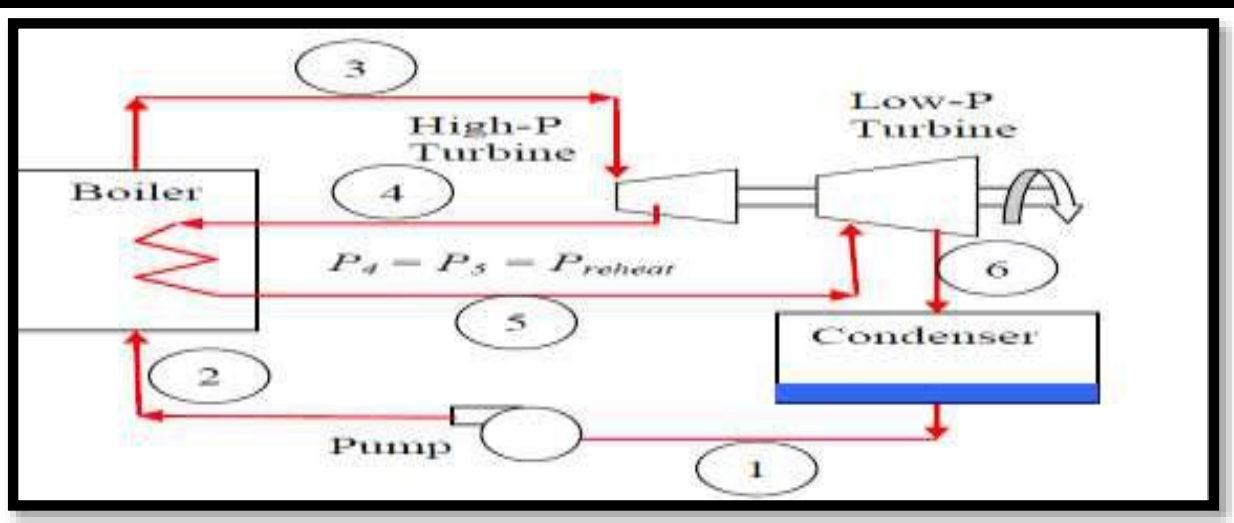

Fig. 2a: Rankine with Re-heat cycle schematic diagram.

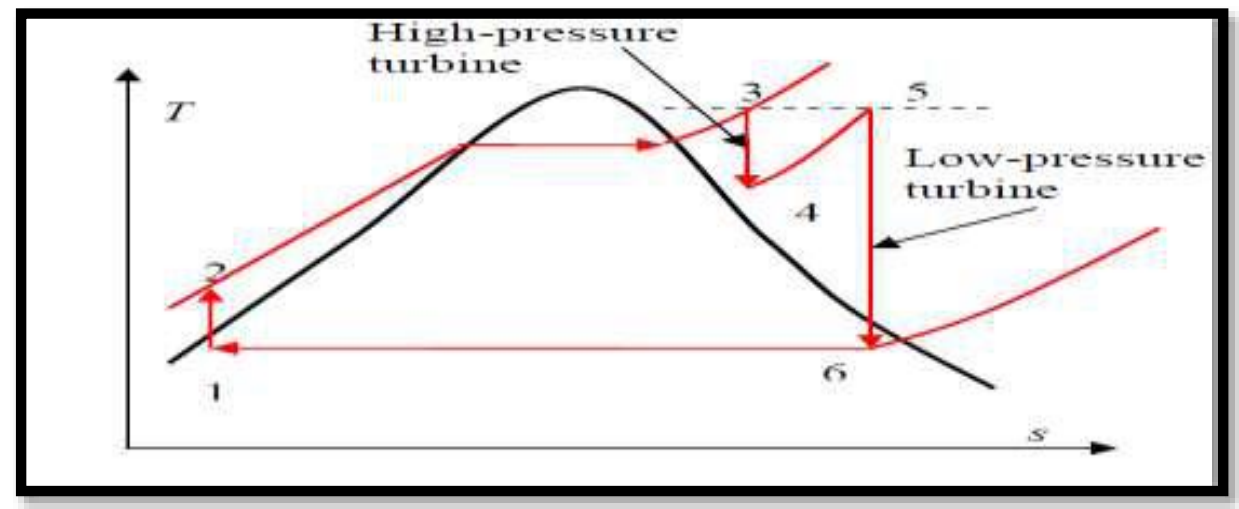

Fig.2b: Rankine with Re-heat cycle T-S diagram.

\section{RESULTS AND DISCUSSIONS}

Steam is the most widely recognized working liquid utilized as a part of vapor power cycles as a result of its numerous alluring attributes, for example, minimal effort, accessibility, and high enthalpy of vaporization. Steam warming is a critical component in steam-control plants. The principle target of warm is to build the power yield and, under specific conditions, the warm productivity of the plant, in this manner enhancing plant execution. In a steam control plant, bolster water radiators permit the sustain water to be raised to the immersion temperature steadily. This minimizes the inescapable irreversibility's connected with warmth exchange to the working liquid. The execution of the warm power plant was investigated with a subcritical and supercritical heater. This kind of heater is working at weights and temperatures of (11MPa and $500 \mathrm{oC})$ for subcritical kettle, or more (22MPa and $600 \mathrm{oC}$ ) for supercritical evaporator [13]. Additionally the warm temperature for low weight turbines was found around to $500 \mathrm{oC}$.This temperature was exhibited in many power plants boilers, for example, cutting edge pummeled coal-let go kettle that intended to item steam at $540 \mathrm{oC}$ for both superheat and warm [14]. And in addition, the examinations manage condenser weight (turbine backpressures) between (5-25 kPa). Turbine backpressures for the most part range from (3.5 $\mathrm{kPa}$ to $16 \mathrm{kPa}$ ) [14]. The power plant was broke down utilizing the above information. The designing condition solver or (EES, v.8.0) was utilized to discover the warmth stream and work done of every cycle component, and the general cycle warm effectiveness by utilizing the above conditions. Presently,

Fig. (3) Shows the impact of pressure proportion (the proportion of warm weight to kettle weight) on the general proficiency of Reheat Rankin Cycle for various heater weights values $(10,14,18,22$, and $26 \mathrm{MPa})$ at consistent condenser weight $(10 \mathrm{Kpa})$, and also steady delta turbine temperatures (high and low weight turbines bays) at $(500 \mathrm{oC})$. Be that as it may, the effectiveness of the cycle increments bit by bit with a light increment in pressure proportion till coming to crest estimation of $(44.12 \%)$ at a pressure proportion of $(0.33)$ at kettle weight of $(\mathrm{PB}=26$ $\mathrm{MPa})$.While the estimations of most noteworthy efficiencies were discovered lower this esteem at other heater weights and lower pressure proportions. The most extreme 
estimation of the proficiency on account of heater weight $(\mathrm{PB}=10 \mathrm{MPa})$, which is discovered equivalent to $(41.71 \%)$ at a pressure proportion equivalent to $(0.25)$. That way to

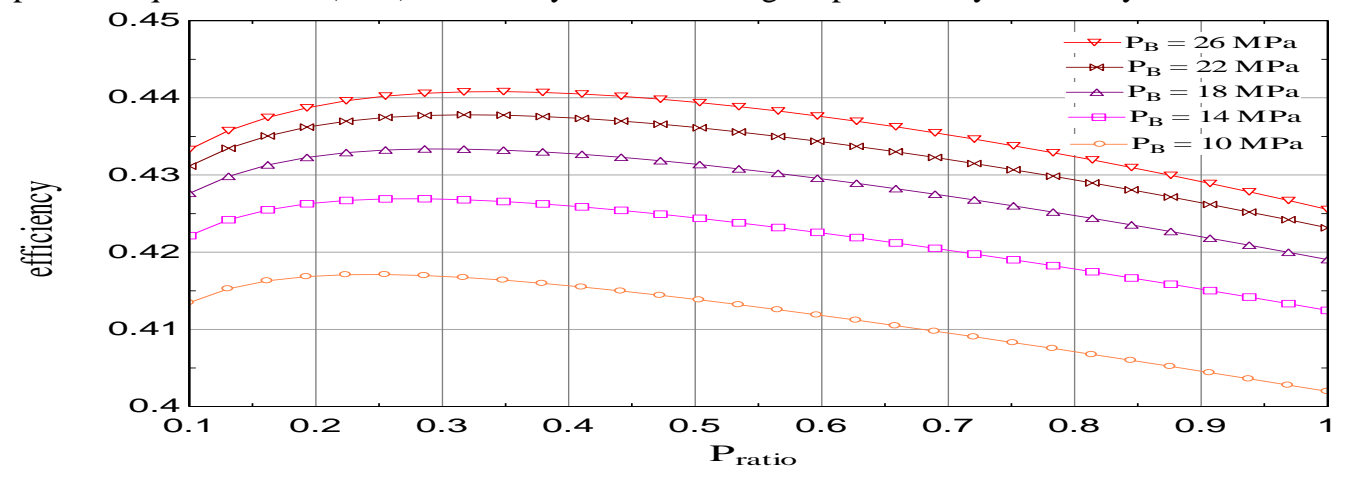

Fig. 3: Overall efficiency as capacity of correlation proportion at various heater weight values.

In Figs. (4) and (5) the impact of warm temperature of second turbine gulf temperature (low weight turbine) has been researched at temperatures near the (high weight turbine) first turbine bay temperature (400-600oC), at a few heater weights $(10,14,18,22$, and $26 \mathrm{MPa})$ and steady condenser weight $(10 \mathrm{kPa})$. The reason for these figures, to examine the cycle proficiency and dryness rubbing (X6) at consistent pressure proportion (0.2) with keeping the turbine channel temperature of high weight turbine near (500oC). From Figs. (4) and (5) plainly the expansion in acquire most extreme effectiveness at low kettle weights; it must be lessen the pressure proportion of the cycle to get a higher proficiency for this cycle.

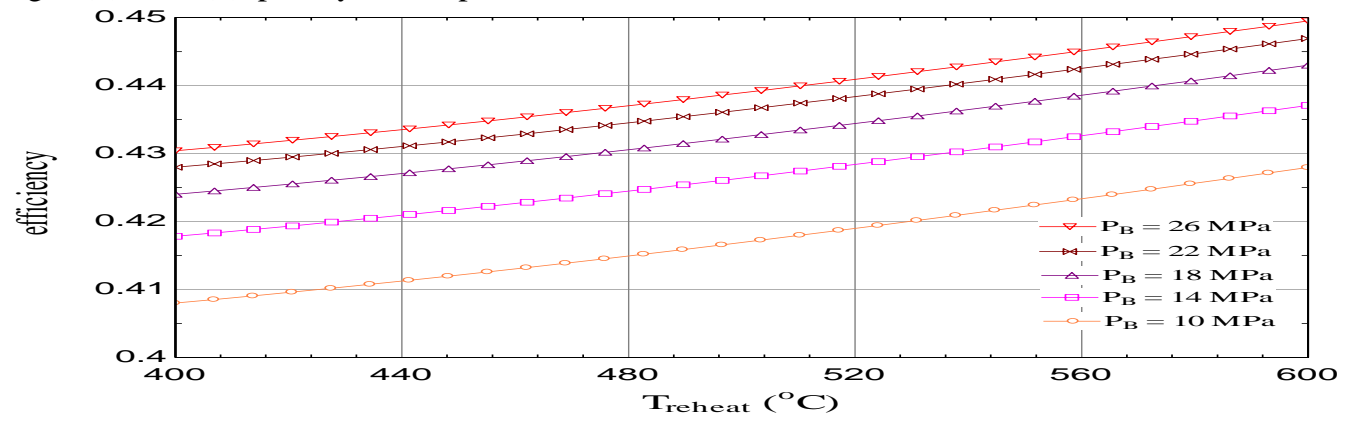

Fig. 4: Overall eefficiency as capacity of warm temperature at various evaporator weight values.

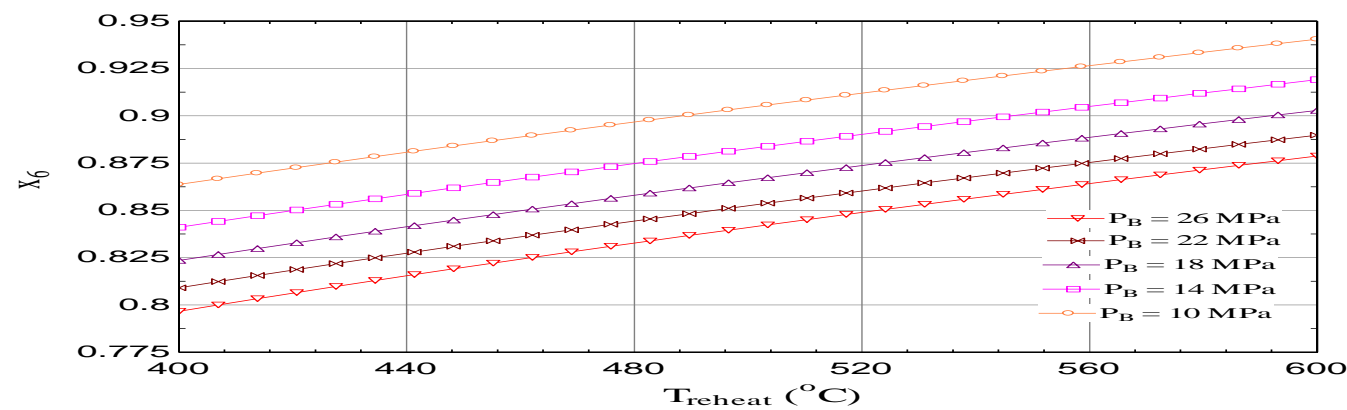

Fig.5: Dryness division as capacity of warms temperature at various kettle weight values.

Fig. (6) Shows the impact of pressure proportion on dryness division (X6) for various kettle weight values $(10,14,18$, warm temperature at all evaporator weights will prompt to enhance the cycle productivity and expanding the estimation of dryness erosion. In this work, the nature of dryness part has been explored to keep up a nature of the dryness grinding around $90 \%$ in the turbine fumes to maintain a strategic distance from the disintegration in sharp edges close to the turbine exit, furthermore to build the vitality transformation effectiveness and working work of turbine as specified in writing [15]. 
low weight turbines) at $(500 \mathrm{oC})$. It appears that lessening in

dryness portion for all kettle weights values.

the cycle pressure proportion prompts to increment in

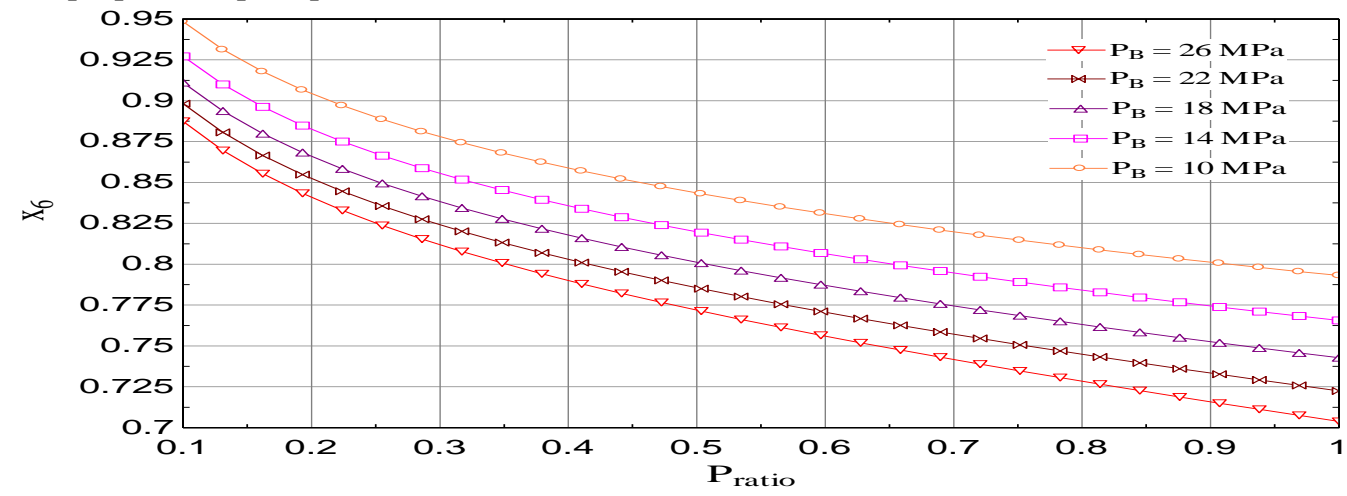

Fig.6: Dryness portion as capacity of pressure proportion at various evaporator weight values.

The impact of condenser weight on general effectiveness has been examined at various evaporator weight values as clear.

In Fig. (7).It clears that, as the condenser weight diminishes, causes to general effectiveness increments for all kettle weight values. Along these lines, the diminishing of the condenser working weight naturally brings down the temperature of the steam, and brings down the temperature at which warmth is rejected. Along these lines the general impact of diminishing the condenser weight is an expansion in the warm productivity of the cycle [11].

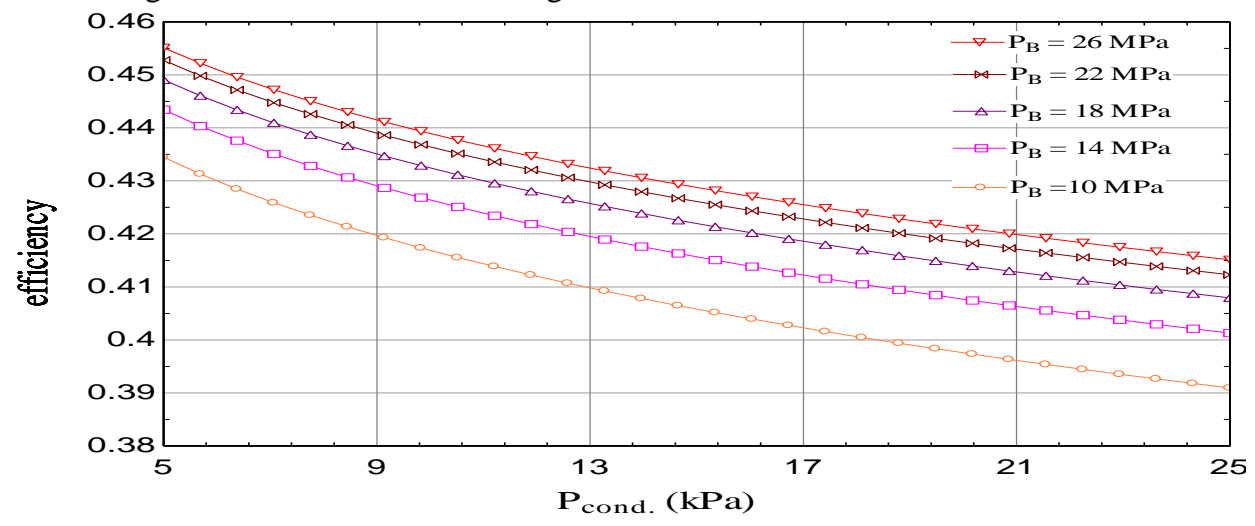

Fig..7: Overall efficency as capacity of condenser weight at various kettle weight values.

It appears to be likewise, as the evaporator weight diminishes causes to lessening in dryness portion as appeared.

In Fig. (8), which adversely impacts on the execution of the low weight turbine. For instance it can be lessen the estimation of condenser weight to $(5 \mathrm{kPa})$ when the heater weight is alter to (10MPa), while can't be decrease condenser weight under $(13 \mathrm{kPa})$ when the kettle weight is equivalent to (26MPa) on the grounds that the disintegration of the turbine at the last stage edges, and in addition the pulverization in the condenser weight increment the misfortune in active vitality of the steam stream because of dragging of dampness particles that have less speed from steam. Thusly, the condenser ideal weight territory is restricted between $(6.9 \mathrm{kPa}$ and $13.8 \mathrm{kPa})$ as specified in writing [4]. 


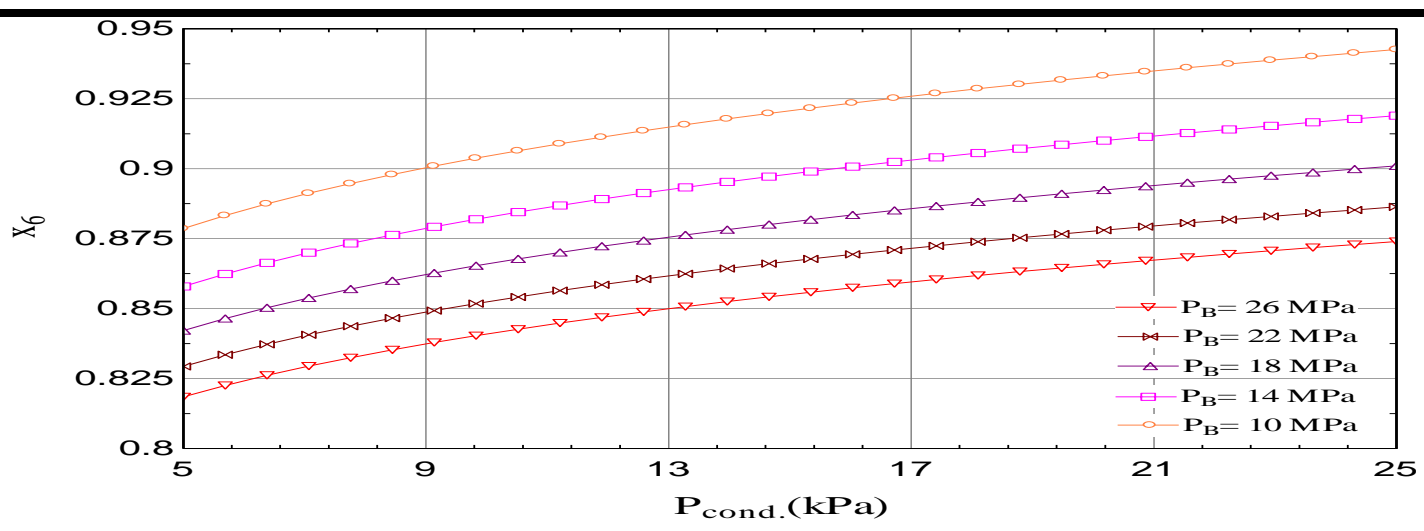

Fig.8: Dryness division as capacity of condenser weight at various evaporator weight values

Finally, Fig. (9) Shows the aggregate system, add up to information warm stream, and warm proficiency as capacity of pressure proportion for a heater weight esteem of $(10$

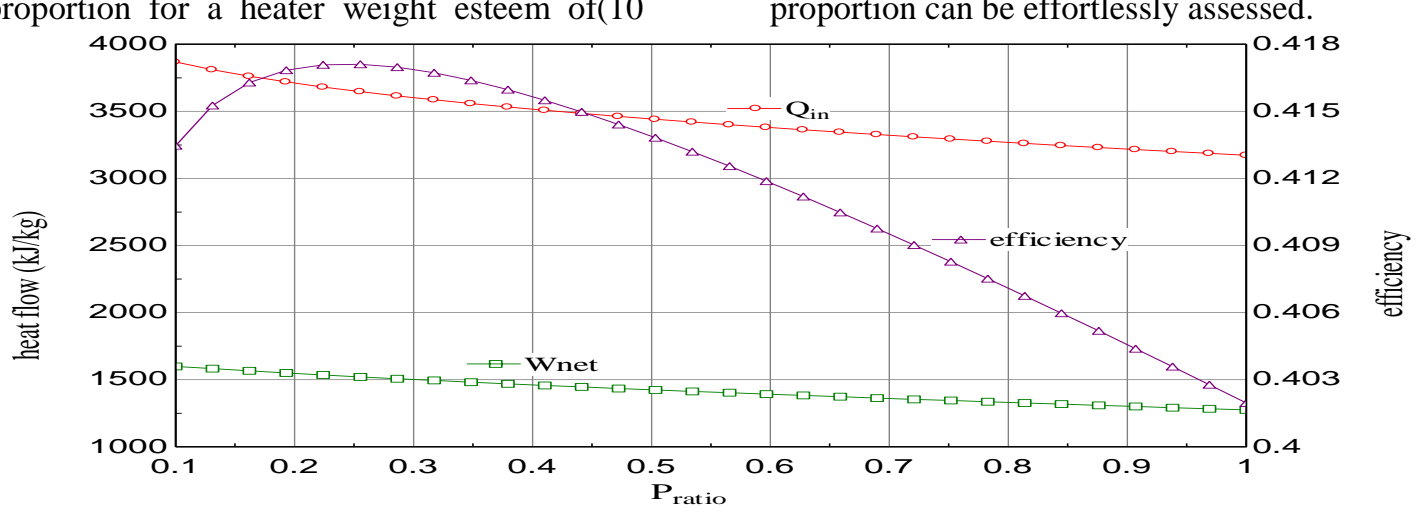

Fig.9: The net work done, total input heat flow, and thermal efficiency as function of compression ratio.

\section{CONCLUSIONS}

A hypothetical examination and investigation for ReheatRankin cycle has been accomplished for various (evaporator, condenser weights, and warm temperatures) to demonstrate its impact on the warm power plants general effectiveness. The effectiveness of a basic Rankin cycle is enhanced by utilizing moderate warm process. Henceforth, the accompanying conclusions have been considered as the synopsis of this work:

1. Increment the warm proficiency of the cycle with increment in estimations of kettle weight at any estimation of the pressure proportion. Additionally unmistakably, the expansion of warm proficiency was finished by increment in pressure proportion values for any evaporator weight esteem until it spans to pinnacle esteem then begins to diminish consistently with ceaselessly increment in the warm temperature values.

2. Increment the estimations of warm productivity with increment in warm stage temperature for any evaporator weight esteem, yet this develop in its esteem turns out to

$\mathrm{MPa})$. In this figure, the warm proficiency, the aggregate system, and aggregate info warm stream for any pressure proportion can be effortlessly assessed.

\section{proportion can be efforlessly assessed.}


Single And Double Reheat IrreversibleRankineCycle",

Journal of the Energy Institute, Vol. 84, No. 4, 2011.

[3] I. Dincer and H. Al-Muslim: Int. J. Energy Res., Vol. 25, pp.727-739, 2001.

[4] Amir vosough, Alirezafalahat, Sadeghvosough, Hasannasresfehani,Azambehjat, and Royanaseri rad. "Improvement Power Plant Efficiency WithCondenser Pressure", International Journal Of Multidisciplinary Sciences And Engineering, Vol. 2, No. 3, pp.3843,JUNE 2011.

[5] K. M. Retzlaff and W. A. Ruegger: "Steam Turbines for Ultra-Supercritical Power Plants", Schenectady, NY, GE Power Systems, 1996.

[6] I. Satyanarayana, A. Gupta, K.G. Rajulu, and K. Susheela, "EXERGY ANALYSIS AND PARAMETRIC STUDY OF REHEAT REGENERATIVE ULTRA SUPERCRITICAL RANKINE CYCLE WITH FEED WATER HEATERS", International Journal of Mechanical and Materials Engineering (IJMME), Vol.6, No.2, pp.250259, 2011.

[7] M. Pandey, T. K. Gogoi, “ ENERGY AND EXERGY ANALYSIS OF A REHEAT REGENERATIVE VAPOR POWER CYCLE", International Journal of Emerging Technology and Advanced Engineering, Vol. 3, Issue 3, pp. 427-434, Feb 2013.

[8] T.Srinivas, Gupta, AVSSKS.and Reddy B.V. "Generalized Thermodynamic Analysis of Steam Power Cycle with ' $n$ ' number of Feed Water Heaters"published in International Journal of Thermodynamics, Vol.10, No.4pp.177-185, 2007. 